\title{
Mechanism of Reduced Lung Injury by High-Frequency Nasal Ventilation in a Preterm Lamb Model of Neonatal Chronic Lung Disease
}

\author{
VIRENDER K. REHAN, JEANETTE FONG, ROBERT LEE, REIKO SAKURAI, ZHENG-MING WANG, MAR JANNA DAHL, \\ ROBERT H. LANE, KURT H. ALBERTINE, AND JOHN S. TORDAY
}

\begin{abstract}
Department of Pediatrics [V.K.R., J.F., R.L., R.S., J.S.T.], Los Angeles Biomedical Research Institute at Harbor-UCLA Medical Center, Torrance, California 90502; Department of Pediatrics [Z.-M.W., M.J.D., R.H.L., K.H.A.], University of Utah, School of Medicine, Salt
\end{abstract} Lake City, Utah 84132

\begin{abstract}
The mechanism underlying the potentially beneficial effects of the "gentler" modes of ventilation on chronic lung disease (CLD) of the premature infant is not known. We have previously demonstrated that alveolar parathyroid hormone-related proteinperoxisome proliferator-activated receptor $\gamma$ (PTHrP-PPAR $\gamma$ ) signaling is critically important in alveolar formation, and this signaling pathway is disrupted in hyperoxia- and/or volutrauma-induced neonatal rat lung injury. Whether the same paradigm is also applicable to CLD, resulting from prolonged intermittent mandatory ventilation (IMV), and whether differential effects of the mode of ventilation on the PTHrP-PPAR $\gamma$ signaling pathway explain the potential benefits of the "gentler" modes of ventilation are not known. Using a wellestablished preterm lamb model of neonatal CLD, we tested the hypothesis that ventilatory support using high-frequency nasal ventilation (HFNV) promotes alveolar PTHrP-PPAR $\gamma$ signaling, whereas IMV inhibits it. Preterm lambs managed by HFNV or IMV for $21 \mathrm{~d}$ following preterm delivery at 132-d gestation were studied by Western hybridization and immunofluorescence labeling for key markers of alveolar homeostasis and injury/repair. In lambs managed by IMV, the abundance of key homeostatic alveolar epithelialmesenchymal markers was reduced, whereas it was significantly increased in the HFNV group, providing a potential molecular mechanism by which "gentler" modes of ventilation reduce neonatal CLD. (Pediatr Res 70: 462-466, 2011)
\end{abstract}

D espite all the advances, neonatal chronic lung disease (CLD) continues to be a major cause of morbidity and mortality in premature infants (1). Histopathologically, neonatal CLD is characterized by alveolar simplification (2). Molecular pathways that may be dysregulated by preterm birth, and that lead to CLD following prolonged mechanical ventilation with oxygen-rich gas, are not fully understood. Alveolar epithelial-mesenchymal interactions are driven by epithelially derived parathyroid hormone-related protein (PTHrP) and mesenchymally derived peroxisome proliferator-activated receptor $\gamma(\operatorname{PPAR} \gamma)$. Because PTHrP and PPAR $\gamma$ are critical for alveolar development (3), we hypothesized that this pathway is disrupted in preterm neonates

Received January 21, 2011; accepted June 3, 2011.

Correspondence: Virender K. Rehan, MD, Department of Pediatrics, Los Angeles Biomedical Research Institute at Harbor UCLA Medical Center, David Geffen School of Medicine at UCLA, 1124 West Carson Street, Torrance, CA 90502,; e-mail: vrehan@labiomed.org

Supported by NIH grants HL75405, HD51857, HD058948, HL55268, and HL62875. The authors report no conflicts of interest. that are managed by prolonged mechanical ventilation with oxygen-rich gas.

PTHrP, secreted by alveolar type II (ATII) cells, acts on its receptor on adjoining alveolar interstitial fibroblasts, which are characterized by the expression of the PTHrP receptor (PTHrP-R) and its down-stream target, PPAR $\gamma(3-5)$. Alveolar interstitial fibroblasts, in turn, secrete leptin, which acts on its receptor on ATII cells (6). This paracrine loop enhances surfactant synthesis and is known to be critically important in maintaining alveolar homeostasis and normal lung development (7).

Using in vitro and in vivo rat models, we have previously shown that disruption of alveolar PTHrP-PPAR $\gamma$ paracrine signaling is a central event in alveolar epithelial-mesenchymal interactions $(3,8)$. Whether the same paradigm is relevant to alveolar simplification seen in neonatal CLD is not known. Therefore, we examined whether dysregulation of PTHrP$\operatorname{PPAR} \gamma$ signaling is also seen in a well-established preterm lamb model of neonatal CLD $(9,10)$.

"Gentler" modes of ventilation such as continuous positive airway pressure or high-frequency ventilation might reduce the occurrence of neonatal CLD $(8,11,12)$. However, the pathways that may contribute to this potentially beneficial effect of the "gentler" modes of ventilation are not known. We also hypothesized that ventilator support using high-frequency nasal ventilation (HFNV) would promote homeostatic PTHrPPPAR $\gamma$ alveolar epithelial-mesenchymal signaling, whereas mechanical ventilation would inhibit it. Enhancing alveolar PTHrP-PPAR $\gamma$ signaling with HFNV may result in less severe neonatal CLD. Therefore, we compared the key molecular markers of PTHrP-PPAR $\gamma$ signaling in preterm lambs supported on either HFNV or intermittent mandatory ventilation (IMV).

Abbreviations: ATII, alveolar type II; CCT- $\alpha$, choline phosphate cytidylyltransferase- $\alpha$; CLD, chronic lung disease; $\mathbf{F i O}_{2}$, fractional inspired oxygen; GAPDH, glyceraldehyde 3-phosphate dehydrogenase; HFNV, high-frequency nasal ventilation; IMV, intermittent mandatory ventilation; PPAR $\boldsymbol{\gamma}$, peroxisome proliferator-activated receptor $\gamma$; PTHrP, parathyroid hormonerelated protein; PTHrP-R, parathyroid hormone-related protein receptor; SP-B, surfactant protein-B; SP-C, surfactant protein-C; $\boldsymbol{\alpha}$-SMA, $\alpha$-smooth muscle actin 


\section{METHODS AND MATERIALS}

This study was approved by the Animal Care Committee of The University of Utah School of Medicine.

Animal model. Preterm lambs $(\sim 132$ d gestation; term $\sim 150$ d) were delivered via cesarean section and divided into two groups: a group managed by HFNV and a group managed by IMV. The methods for the chronic ventilation model using preterm lambs have been reported $(9,10,13-19)$. Pregnant ewes that carried single or twin fetuses at 130-132 d of gestation (term $\sim 150 \mathrm{~d}$ gestation) were used. Pregnant ewes were given an intramuscular injection of dexamethasone phosphate $(6 \mathrm{mg}$; Vedco, Inc., St. Joseph, $\mathrm{MO}), \sim 24 \mathrm{~h}$ before operative delivery. On the day of delivery, the ewes were given i.m. ketamine hydrochloride (10-20 mg/kg; Fort Dodge Laboratories, Fort Dodge, IA), followed by inhalation anesthesia with $1 \%$ isoflurane (Abbott Laboratories, North Chicago, IL). We exposed each fetus by midline hysterotomy, placed catheters in the common carotid artery and external jugular vein, and intubated them with a cuffed endotracheal tube (3.5 to 4.0 French), through which $10 \mathrm{~mL}$ of lung liquid was aspirated and replaced with Survanta $(2.5 \mathrm{~mL}$; NDC 0074-1040-08, Ross Products Division, Abbott Laboratories, Columbus, $\mathrm{OH})$. For the fetuses that were assigned to HFNV (described below), an uncuffed oral/nasal true Murphy tube (3.0 to $4.0 \mathrm{~mm} \mathrm{ID;}$ $13 \mathrm{~cm}$ length) was also inserted through a nostril to reach the middle of the length of the nasal cavity $(5-6 \mathrm{~cm}$ of the $-10 \mathrm{~cm}$ long cavity). Lidocaine ( $1 \%$ solution; Hospira, Inc.) was injected s.c. along the nostril to minimize pain and discomfort. Fetuses were removed from the uterus, and their umbilical cords were tied and cut.

During the initial 2-3 h of resuscitation, all preterm lambs were managed by IMV (model 15215; Bird VIP ventilator, Palm Springs, CA) with warmed and humidified $100 \%$ oxygen. Initial ventilator settings were a respiratory rate of $60 \mathrm{breaths} / \mathrm{min}$, inspiratory time of $0.30 \mathrm{~s}$, and a positive end-expiratory pressure of $8 \mathrm{~cm} \mathrm{H}_{2} \mathrm{O}$. Peak inspiratory pressure was adjusted to attain a target $\mathrm{PaCO}_{2}$ between 45 and $60 \mathrm{~mm} \mathrm{Hg}$, and a pH between 7.25 and 7.35, and a fractional inspired oxygen $\left(\mathrm{FiO}_{2}\right)$ of 1.0. The target expiratory tidal volume, measured by the ventilator, was 5 to $7 \mathrm{~mL} / \mathrm{kg} / \mathrm{breath}$. A second treatment with Survanta $(2.5 \mathrm{~mL})$ was given at 5 to $10 \mathrm{~min}$ of life. The concentration of inspired $\mathrm{O}_{2}$ was decreased to maintain the target $\mathrm{PaO}_{2}$ between 60 and $80 \mathrm{~mm}$ $\mathrm{Hg}$. Maintaining the oxygenation target required different $\mathrm{FiO}_{2}$ between the groups. For the IMV group, the range for $\mathrm{FiO}_{2}$ was $0.35-0.50$, whereas in the HFNV group, the range for $\mathrm{FiO}_{2}$ was $0.25-0.35$ (data not shown; Ref. 9). To stimulate ventilatory drive, all lambs were treated i.v. with a loading dose of caffeine citrate within $30 \mathrm{~min}$ of delivery $(15 \mathrm{mg} / \mathrm{kg}$, given over $2 \mathrm{~h}$; Mead Johnson \& Company, Evansville, IN). Caffeine citrate was given once daily thereafter at a dose of $5 \mathrm{mg} / \mathrm{Kg}$.

For the preterm lambs assigned to the HFNV group, weaning from IMV began at $2-3 \mathrm{~h}$ of age. When the lambs breathed spontaneously ( $3-4 \mathrm{~h}$ of age), the ventilatory circuit was changed to a high-frequency flow interrupter ventilator (Percussionaire Corp., Sandpoint, ID). The settings were $20-25 \mathrm{~cm}$ $\mathrm{H}_{2} \mathrm{O}$ for amplitude, 8-12 $\mathrm{cm} \mathrm{H}_{2} \mathrm{O}$ for mean pressure, 5-7 $\mathrm{cm} \mathrm{H}_{2} \mathrm{O}$ for end-expiratory pressure, and $10 \mathrm{~Hz}$ for rate.

Each group was managed with the assigned ventilatory strategy for $21 \mathrm{~d}$. Two preterm lambs were studied simultaneously. The order of ventilation mode was alternated so that consecutive preterm lambs were not managed by the same ventilation mode. Preterm lambs were kept prone in a veterinary sling mounted on a heated bed. Saline and dextrose solutions were administered i.v., as were antibiotics and sedatives (pentobarbital sodium; Abbott Laboratories; North Chicago, IL; and buprenorphine hydrochloride, $5 \mu \mathrm{g} / \mathrm{kg}$ every 3 h; Reckitt \& Colman Pharmaceuticals, Richmond, VA). The preterm lambs assigned to IMV received $3-5 \mathrm{mg} / \mathrm{kg}$ of pentobarbital as needed to minimize discomfort associated with endotracheal intubation. This dosage prevented spontaneous breathing. The preterm lambs assigned to HFNV were given 1-2 $\mathrm{mg} / \mathrm{kg}$ of pentobarbital so that they breathed spontaneously. Vascular pressures and heart rate were continuously recorded (V6400; SurgVet, Inc.; Waukesha, WI). Arterial blood gases and $\mathrm{pH}$ and plasma concentrations of glucose and electrolytes were measured hourly. Plasma concentrations of total protein and hematocrit were measured at 6-h intervals. An orogastric feeding tube was used for enteral feedings, using fresh colostrum from the ewes, beginning at $\sim 4 \mathrm{~h}$ of life $(3-5 \mathrm{~mL} / \mathrm{kg}$ every $2 \mathrm{~h}$ ). The feeding tube was withdrawn between feedings. The volume of colostrum was increased gradually by $5 \mathrm{~mL}$ increments, as tolerated, to attain a goal of 60 $\mathrm{kcal} / \mathrm{kg} / \mathrm{d}$ of total energy substrate. We monitored total fluid intake (saline, dextrose, and milk) and output (urine and stool), and made adjustments to maintain fluid homeostasis, as indicated by urine output $(>1-2 \mathrm{~mL} / \mathrm{kg} / \mathrm{h})$ and blood pressure $(>45 \mathrm{~mm} \mathrm{Hg}$ ). Chest radiographs were taken daily to assess lung inflation volume and to identify atelectasis. None of the preterm lambs developed air leaks. Indices of infection were monitored by daily leukocyte total and differential cell counts and by core body temperature. None of the preterm lambs required treatment with pressors.
At the end of the 21-d study, the lambs were given heparin (1000 U, i.v.). The HFNV group was reintubated and managed for $<1$ min with the same ventilator settings during HFNV. All lambs were killed by overdosing them with pentobarbital $(60 \mathrm{mg} / \mathrm{kg}$ pentobarbital sodium solution; i.v.; Ovation Pharmaceuticals, Inc., Deerfield, IL). The chest was opened, the trachea was ligated at end inspiration to minimize atelectasis, and the lungs and heart were removed as a block. The whole left lung was insufflated with $10 \%$ buffered neutral formalin to a static pressure of $25 \mathrm{~cm} \mathrm{H}_{2} \mathrm{O}$. Fixed-lung displacement volume was measured by suspension in formalin before the lung was stored in fixative at $4^{\circ} \mathrm{C}$ for $24 \mathrm{~h}$. Paraffin-embedded tissue blocks were prepared and cut for routine histologic observation $(9,10)$. The right lung was cut into small pieces $(\sim 0.5 \mathrm{gm})$ that were frozen in liquid nitrogen and stored at $-80^{\circ} \mathrm{C}$. The frozen lung tissue was kept for analysis by Western hybridization and immunofluorescence labeling for key functional markers of alveolar homeostasis and injury/repair.

Western hybridization. Protein extraction and Western hybridization were performed using standard methods, as described by us previously (20). The specific markers analyzed by Western hybridization included surfactant protein (SP)-B, SP-C, choline-phosphate cytidylyltransferase- $\alpha$ (CCT- $\alpha$ ), leptin receptor (leptin R), PTHrP PTHrP-R, PPAR $\gamma, \alpha$-smooth muscle actin $(\alpha-$ SMA), and calponin. Glyceraldehyde 3-phosphate dehydrogenase (GAPDH) was used as a housekeeping gene to normalize the Western data as we have found it to be a nonvariable control marker in this (data not shown) and other studies of the developing lung $(4,5,20-22)$.

Immunofluorescence. Immunofluorescence double labeling was performed for PPAR $\gamma /$ Pro-SP-C, PPAR $\gamma /$ vimentin, PTHrP-R/pro-SP-C, and PTHrP-R/vimentin, as described previously $(9,10)$.

\section{RESULTS}

Initially, we profiled the ontogeny of functional markers for alveolar mesenchymal and epithelial cells at $132 \mathrm{~d}$ and $145 \mathrm{~d}$ gestation (term $\sim 150 \mathrm{~d}$ ) and at term (Fig. 1). The PTHrP-R and $\alpha$-SMA are functional markers of lipofibroblasts and myofibroblasts, respectively. Developmentally, PTHrP-R abundance increased progressively between gestational d 132 and term (240\% increase). $\alpha$-SMA also increased during this time frame (40\% increase). PTHrP, SP-B, and SP-C are functional markers of alveolar epithelial type II (ATII) cells. These functional markers also increased between gestational d 132 and term by 120,15 , and $100 \%$ for PTHrP, SP-B, and SP-C, respectively.

We then determined the effects of HFNV versus IMV on SP abundance by ATII cells (Fig. 2). SP-B abundance was significantly stimulated by HFNV (37\%); IMV significantly decreased SP-B abundance compared with the HNFV (59\%) group. SP-C abundance was significantly increased by HFNV (200\%) compared with term and $40 \%$ compared with IMV. The beneficial effect of HFNV versus IMV was further corroborated by examining the abundance of the ATII cell functional marker CCT- $\alpha$, the rate-limiting enzyme in surfactant phospholipid synthesis (Fig. 3). Choline phosphate cytidylyltransferase- $\alpha$ abundance was significantly enhanced by HNFV (40\%) but was unaffected by IMV. Leptin R abundance, another functional marker of the ATII cell, was also significantly increased by HFNV $(\sim 60 \%)$, but was unaffected by IMV.

We next examined the effects of HFNV versus IMV on the levels of functional markers of alveolar interstitial lipofibroblasts (Fig. 4). PTHrP-R abundance was significantly increased by HFNV (77\%), but not by IMV. PPAR $\gamma$ abundance was significantly increased by HFNV (57\%), but was also unaffected by IMV. As for functional markers of myofibroblasts, $\alpha$-SMA was significantly inhibited by HFNV (30\%), but was unaffected by IMV (Fig. 5). In contrast, calponin was 

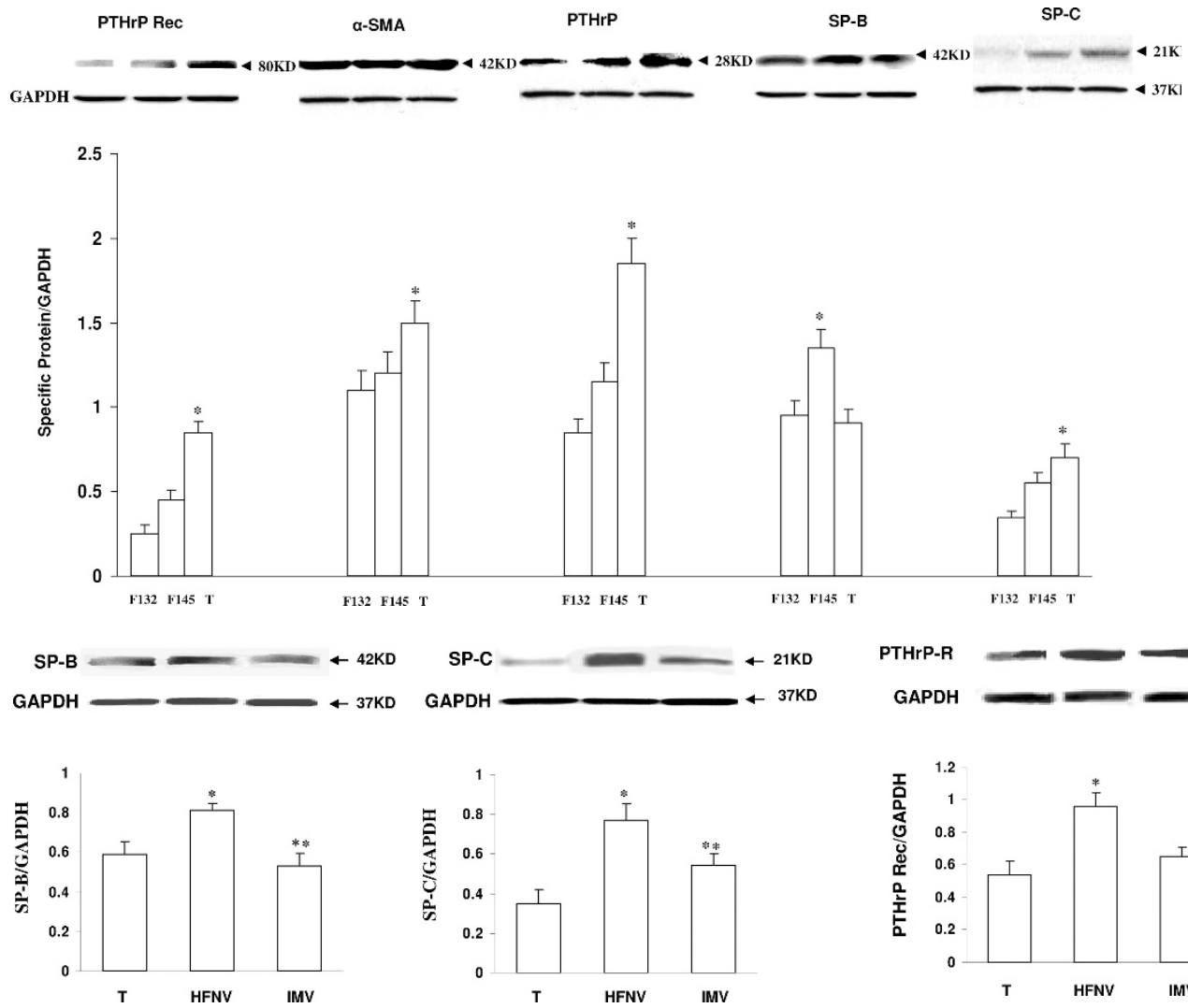

Figure 2. Effect of ventilatory strategy on epithelial differentiation markers SP-B and -C. SP-B abundance was significantly greater in the HFNV group, whereas it was significantly decreased in the IMV group, compared with the term (T) group. SP-C abundance was increased significantly by both HFNV and IMV, but more so by HFNV $(* p<0.05$ vs term; $* *<0.05$ vs HFNV; values are SEM; $n=5$ ).
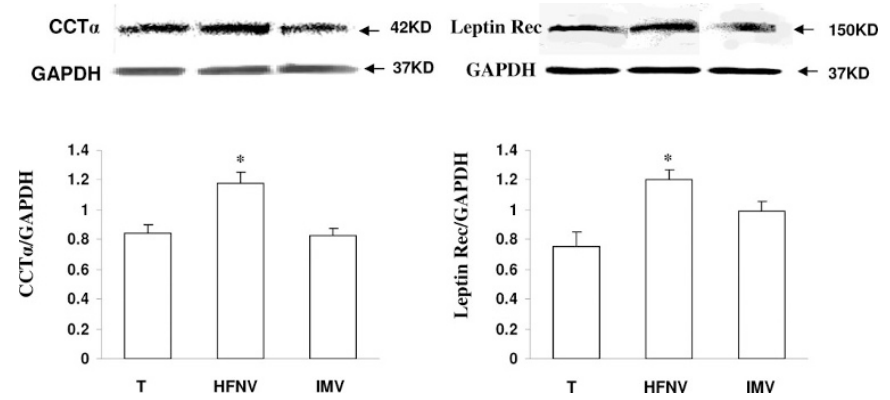

Figure 3. Effect of ventilatory strategy on epithelial differentiation markers choline phosphate cytidylyltransferase- $\alpha(\mathrm{CCT}-\alpha)$ and leptin rec. Abundance of both CCT- $\alpha$ and leptin rec were increased significantly by HNFV, but were unaffected by IMV $\left({ }^{*} p<0.05 v s\right.$ term $(\mathrm{T})$; values are SEM; $\left.n=5\right)$.

unaffected by HFNV, but was significantly increased by IMV (20\%).

Analysis of lung histologic sections by immunofluorescence localized PPAR $\gamma$, pro-SP-C, PTHrP, and PTHrP-R based on our Western analysis findings (Fig. 6). Lung tissue sections from the HNFV group showed obvious immunostaining for PPAR $\gamma$, pro-SP-C, and PTHrP-R, whereas there was less immunostaining for vimentin. However, lung tissue sections from the IMV group showed increased staining for vimentin, also increasing pro-SP-C staining, while having no effect on either PPAR $\gamma$ or PTHrP-R staining.

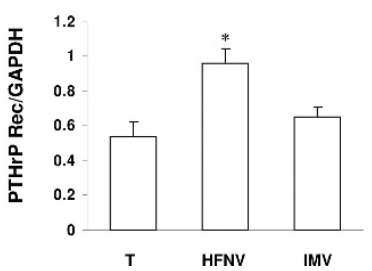
(T); values are SEM; $n=5$ ).

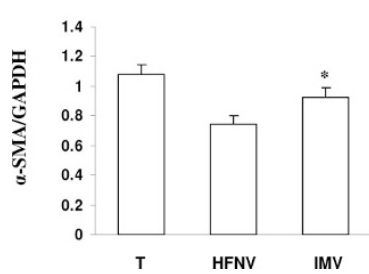
are SEM; $n=5$ ).
Figure 1. Developmental abundance profile for markers of alveolar homeostasis. The abundance of PTHrP-R and $\alpha$-SMA, functional markers of lipofibroblasts and myofibroblasts, respectively, increased between gestational d 132 and term. Similarly, abundance of PTHrP, SP-B, and SP-C, functional markers of alveolar epithelial type II cells, also increased between gestational d 132 and term $(\mathrm{T} ; * p<0.05$ vs F132 group; values are SEM; $n=5$ ).
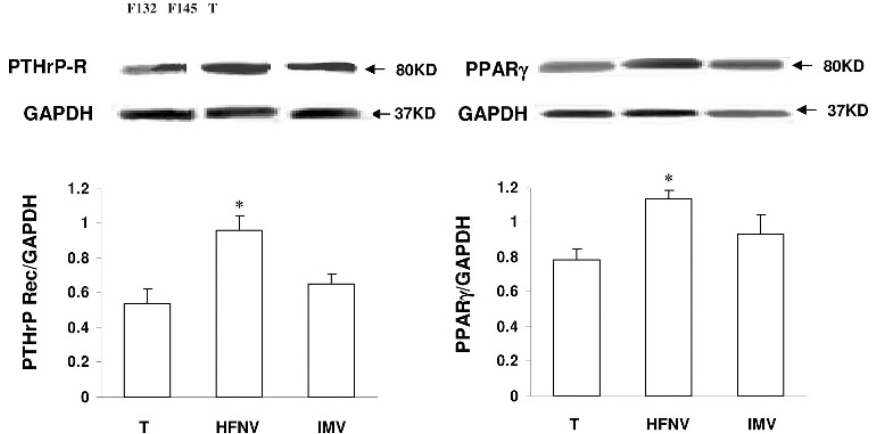

Figure 4. Effect of ventilatory strategy on alveolar interstitial lipofibroblast differentiation markers PTHrP-R and PPAR $\gamma$. PTHrP-R abundance was significantly increased by both HFNV and IMV. PPAR $\gamma$ abundance was significantly increased by HFNV, but was unaffected by IMV $(* p<0.05 v$ s term
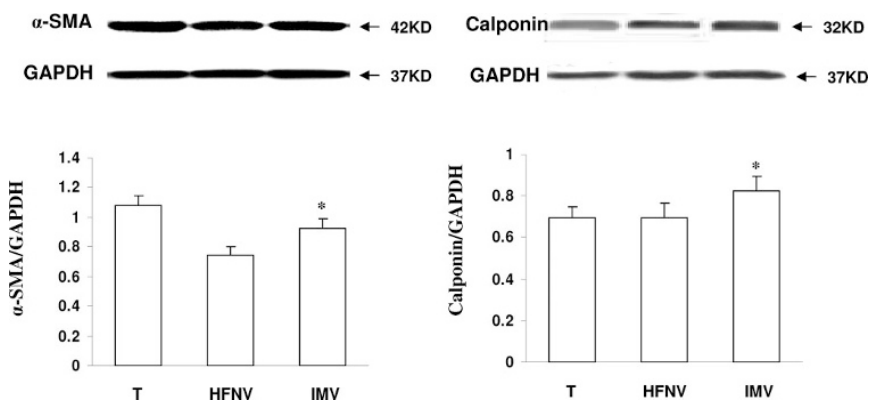

Figure 5. Effect of ventilatory strategy on alveolar interstitial myofibroblast differentiation markers $\alpha$-SMA and calponin. $\alpha$-SMA was significantly inhibited by HFNV, but was unaffected by IMV. Calponin was unaffected by HFNV, but was significantly increased by IMV $\left({ }^{*} p<0.05 v\right.$ s term $(\mathrm{T})$; values

\section{DISCUSSION}

The present data provide important molecular insights to the well-described differential effects of HFNV versus IMV on the risk of neonatal CLD in preterm newborns. On the one hand, HFNV promoted the coordinate expression of the epithelial (SP-B, SP-C, CCT- $\alpha$, and leptin-R) and mesenchymal (PTHrP-R and PPAR $\gamma$ ) signaling components of the PTHrPPPAR $\gamma$ paracrine signaling pathway for alveolar homeostasis (3-8). On the other hand, IMV either inhibited such signaling or failed to stimulate this prohomeostatic mechanism during a critical period in alveolarization. The net result of these two 
Term
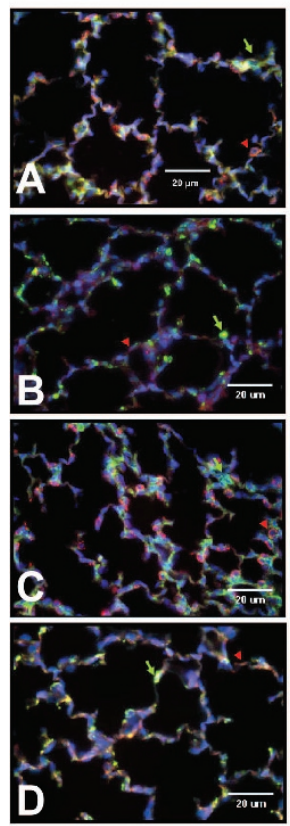

Figure 6. Validation of the effects of ventilatory strategy on alveolar differentiation markers by immunofluorescence. Immunofluorescence double labeling with PPAR $\gamma /$ pro-SP-C (green/red) (A), PPAR $\gamma /$ Vimentin (red/green) $(B)$, PTHrP-R/pro-SP-C (green/red) $(C)$, and PTHrP-R/Vimentin (red/green) $(D)$ confirmed that HNFV increased staining for PPAR $\gamma$, pro-SP-C, and PTHrP-R, while inhibiting the staining of vimentin. On the other hand, IMV increased the staining for vimentin, while also increasing pro-SP-C staining, and having no effect on PPAR $\gamma$ and PTHrP staining. Scale bar $=20 \mu \mathrm{m}$.

ventilatory modalities would, as expected, be either pro- or antihomeostatic causing a decreased or increased incidence of neonatal CLD, respectively.

Physiologically, PTHrP promotes alveolar homeostasis in the developing lung through a paracrine pathway, structurally and functionally linking the maturation of the endoderm and mesoderm $(3,7,23)$. PTHrP is expressed and secreted by ATII cells under the influence of stretch $(7,24,25)$, subsequently binding to its cognate receptor on adepithelial fibroblasts, inducing the lipofibroblast phenotype. The lipofibroblast serves two major purposes in the ontogeny of the alveolar acinus - it is cytoprotective against oxygen-free radicals (26) and produces leptin (5), which stimulates surfactant synthesis by the ATII cell by binding to its receptor on the ATII cell (5-7). The expression of leptin and its receptor are also stimulated by stretching of the alveolar wall, generating additive, or synergistic interactions between PTHrP and leptin for surfactant production $(24,25,27)$. This exquisite interlocking of ligands and receptors, regulated by the stretching of the alveolar wall, functionally integrates the structure and function of the alveolus.

The PTHrP-PPAR $\gamma$-mediated epithelial-mesenchymal paracrine signaling mechanism of alveolar acinar development and homeostasis also predicts rational targets for failed signaling in disease. We have shown that in the absence of PTHrP-PPAR $\gamma$ signaling, due to ATII cell immaturity and/or injury (barotrauma $(24,25,27)$, hyperoxia $(20,28,21)$, infection (22), or nicotine (29-32), the lipofibroblast transdifferentiates into a myofibroblast because of the down-regulation of $\operatorname{PPAR} \gamma$, the nuclear transcription factor necessary for adipocyte differentiation (33). Conversely, treatment of any one of these mechanisms of cell-molecular signaling breakdown with a PPAR $\gamma$ agonist, such as rosiglitazone or prostaglandin $\mathrm{J}_{2}$, can either prevent $(20-22,31,32)$ or reverse (30) the failure of cell-cell signaling that causes neonatal CLD, providing a possible targeted molecular approach to effectively prevent or treat neonatal CLD based on its pathophysiology.

It is important to note that there are key limitations to our study: 1) because both groups of preterm lambs were resuscitated with IMV for 2 to $3 \mathrm{~h}$ before weaning the highfrequency group to HFNV, it is possible that the lung injury initiated even during the brief period of IMV before switching to HFNV might have obscured the differences in the molecular markers examined by us. However, if that were the case, the actual molecular differences would have been even more pronounced than those noted by us; and 2) as noted in our previous study (9), the other potential confounding differences between the two groups of preterm lambs were the amounts of sedatives used and the enteral nutrition delivered. Therefore, we cannot exclude the possibility that some of the differences in the expression of the molecular markers observed by us between the two groups were because of the greater amount of sedatives and decreased amount of enteral feeding in the IMV group versus the HFNV group.

In summary, our results show that in a preterm lamb model of CLD, HFNV enhances homeostatic alveolar epithelialmesenchymal paracrine signaling driven by PTHrP-PPAR $\gamma$, whereas IMV inhibits it. We therefore speculate that decreased neonatal CLD in infants supported by HFNV is likely due to its positive effect on PTHrP-PPAR $\gamma$-driven alveolar homeostatic epithelial-mesenchymal signaling. Because the inherent immaturity of alveolar structure and function of the preterm lung are physiologic limits to which mechanical ventilatory support can be reduced in the face of the need for adequate amounts of circulating oxygen, we further speculate that combining treatment with PTHrP/PPAR $\gamma$ agonists with HFNV may further diminish or eliminate the risk of neonatal CLD in the future.

Acknowledgment. We thank Dr. Afshan Abbasi for her help in coordinating some of the work included in this manuscript.

\section{REFERENCES}

1. Walsh MC, Szefler S, Davis J, Allen M, Van Marter L, Abman S, Blackmon L, Jobe A 2006 Summary proceedings from the bronchopulmonary dysplasia group. Pediatrics 117:S52-S56

2. Jobe AJ 1999 The new BPD: an arrest of lung development. Pediatr Res 46:641-643

3. Torday JS, Rehan VK 2007 Developmental cell/molecular biologic approach to the etiology and treatment of bronchopulmonary dysplasia. Pediatr Res 62:2-7

4. Rehan VK, Sugano S, Wang Y, Santos J, Romero S, Dasgupta C, Keane MP, Stahlman MT, Torday JS 2006 Evidence for the presence of lipofibroblasts in human lung. Exp Lung Res 32:379-393

5. Torday JS, Torres E, Rehan VK 2003 The role of fibroblast transdifferentiation in lung epithelial cell proliferation, differentiation, and repair in vitro. Pediatr Pathol Mol Med 22:189-207

6. Torday JS, Sun H, Wang L, Torres E, Sunday ME, Rubin LP 2002 Leptin mediates the parathyroid hormone-related protein paracrine stimulation of fetal lung maturation. Am J Physiol Lung Cell Mol Physiol 282:L405-L410

7. Torday JS, Rehan VK 2002 Stretch-stimulated surfactant synthesis is coordinated by the paracrine actions of PTHrP and leptin. Am J Physiol Lung Cell Mol Physiol 283:L130-L135 
8. Cerny L, Torday JS, Rehan VK 2008 Prevention and treatment of bronchopulmonary dysplasia: contemporary status and future outlook. Lung 186:75-89

9. Reyburn B, Li M, Metcalfe DB, Kroll NJ, Alvord J, Wint A, Dahl MJ, Sun J, Dong L, Wang ZM, Callaway C, McKnight RA, Moyer-Mileur L, Yoder BA, Null DM, Lane RH, Albertine KH 2008 Nasal ventilation alters mesenchymal cell turnover and improves alveolarization in preterm lambs. Am J Respir Crit Care Med 178:407-418

10. Albertine KH, Dahl MJ, Gonzales LW, Wang ZM, Metcalfe D, Hyde DM, Plopper CG, Starcher BC, Carlton DP, Bland RD 2010 Chronic lung disease in preterm lambs: effect of daily vitamin A treatment on alveolarization. Am J Physiol Lung Cell Mol Physiol 299:L59-L72

11. Van Marter LJ 2005 Strategies for preventing bronchopulmonary dysplasia. Curr Opin Pediatr 17:174-180

12. Keszler M, Modanlou HD, Brudno DS, Clark FI, Cohen RS, Ryan RM, Kaneta MK, Davis IM 1997 Multicenter controlled clinical trial of high-frequency jet ventilation in preterrn infants with uncomplicated respiratory distress syndrome. Pediatrics 100:593-599

13. Pierce RA, Albertine KH, Starcher BC, Bohnsack JF, Carlton DP, Bland RD 1997 Chronic lung injury in preterm lambs: disordered pulmonary elastin deposition. Am J Physiol 272:L452-L460

14. Albertine KH, Jones GP, Starcher BC, Bohnsack JF, Davis PL, Cho SC, Carlton DP, Bland RD 1999 Chronic lung injury in preterm lambs. Disordered respiratory tract development. Am J Respir Crit Care Med 159:945-958

15. Bland RD, Albertine KH, Carlton DP, Kullama L, Davis P, Cho SC, Kim BI, Dahl M, Tabatabaei N 2000 Chronic lung injury in preterm lambs: abnormalities of the pulmonary circulation and lung fluid balance. Pediatr Res 48:64-74

16. MacRitchie AN, Albertine KH, Sun J, Lei PS, Jensen SC, Freestone AA, Clair PM Dahl MJ, Godfrey EA, Carlton DP, Bland RD 2001 Reduced endothelial nitric oxide synthase in lungs of chronically ventilated preterm lambs. Am J Physiol Lung Cell Mol Physiol 281:L1011-L1020

17. Bland RD, Albertine KH, Pierce RA, Starcher BC, Carlton DP 2003 Impaired alveolar development and abnormal lung elastin in preterm lambs with chronic lung injury: potential benefits of retinol treatment. Biol Neonate 84:101-102

18. Bland RD, Albertine KH, Carlton DP, MacRitchie AJ 2005 Inhaled nitric oxide effects on lung structure and function in chronically ventilated preterm lambs. Am J Respir Crit Care Med 172:899-906

19. Bland RD, Xu L, Ertsey R, Rabinovitch M, Albertine KH, Wynn KA, Kumar VH Ryan RM, Swartz DD, Csiszar K, Fong KS 2007 Dysregulation of pulmonary elastin synthesis and assembly in preterm lambs with chronic lung disease. Am J Physiol Lung Cell Mol Physiol 292:L1370-L1384

20. Dasgupta C, Sakurai R, Wang Y, Guo P, Ambalavanan N, Torday JS, Rehan VK 2009 Hyperoxia-induced neonatal rat lung injury involves activation of TGF- $\beta$ and
Wnt signaling and is protected by rosiglitazone. Am J Physiol Lung Cell Mol Physiol 296:L1031-L1041

21. Rehan VK, Wang Y, Patel S, Santos J, Torday JS 2006 Rosiglitazone, a peroxisome proliferator-activated receptor-gamma agonist, prevents hyperoxia-induced neonatal rat lung injury in vivo. Pediatr Pulmonol 41:558-569

22. Rehan VK, Drgan-Batra SK, Wang Y, Cerny L, Sakurai R, Santos J, Beloosesky R, Gayle D, Torday JS 2007 A paradoxical temporal response of the PTHrP/ PPARgamma signaling pathway to lipopolysaccharide in an in vitro model of the developing rat lung. Am J Physiol Lung Cell Mol Physiol 293:L182-L190

23. Torday JS, Rehan VK 2006 Up-regulation of fetal rat lung parathyroid hormonerelated protein gene regulatory network down-regulates the Sonic Hedgehog/Wnt/ betacatenin gene regulatory network. Pediatr Res 60:382-388

24. Sanchez-Esteban J, Cicchiello LA, Wang Y, Tsai SW, Williams LK, Torday JS Rubin LP 2001 Mechanical stretch promotes alveolar epithelial type II cell differentiation. J Appl Physiol 91:589-595

25. Sanchez-Esteban J, Tsai SW, Sang J, Qin J, Torday JS, Rubin LP 1998 Effects of mechanical forces on lung-specific gene expression. Am J Med Sci 316:200-204

26. Torday JS, Torday DP, Gutnick J, Qin J, Rehan V 2001 Biologic role of fetal lung fibroblast triglycerides as antioxidants. Pediatr Res 49:843-849

27. Torday JS, Sanchez-Esteban J, Rubin LP 1998 Paracrine mediators of mechanotransduction in lung development. Am J Med Sci 316:205-208

28. Boros LG, Torday JS, Paul Lee WN, Rehan VK 2002 Oxygen-induced metabolic changes and transdifferentiation in immature fetal rat lung lipofibroblasts. Mol Genet Metab 77:230-236

29. Rehan VK, Asotra K, Torday JS 2009 The effects of smoking on the developing lung: insights from a biologic model for lung development, homeostasis, and repair. Lung 187:281-289

30. Rehan VK, Sakurai R, Wang Y, Santos J, Huynh K, Torday JS 2007 Reversal of nicotine-induced alveolar lipofibroblast-to-myofibroblast transdifferentiation by stimulants of parathyroid hormone-related protein signaling. Lung 185:151-159

31. Rehan VK, Wang Y, Sugano S, Romero S, Chen X, Santos J, Khazanchi A, Torday JS 2005 Mechanism of nicotine-induced pulmonary fibroblast transdifferentiation. Am J Physiol Lung Cell Mol Physiol 289:L667-L676

32. Rehan VK, Wang Y, Sugano S, Santos J, Patel S, Sakurai R, Boros LG, Lee WP, Torday JS 2007 In utero nicotine exposure alters fetal rat lung alveolar type II cell proliferation, differentiation, and metabolism. Am J Physiol Lung Cell Mol Physiol 292:L323-L333

33. Tontonoz P, Hu E, Spiegelman BM 1994 Stimulation of adipogenesis in fibroblasts by PPAR gamma 2, a lipid-activated transcription factor. Cell 79:1147-1156 